Eur Surg (2018) 50:41-44

https://doi.org/10.1007/s10353-018-0517-1

CrossMark

\section{Reality and truth in surgery}

\author{
Martin Riegler
}

Published online: 12 March 2018

(C) Springer-Verlag GmbH Austria, part of Springer Nature 2018

\section{Dear reader,}

welcome to the present issue of European Surgery, presenting a splendid rainbow of articles including the fascinating spectra of colorectal, gastrointestinal, bilio-digestive, esophageal, and minimally invasive surgery. Main focus addresses the importance of surgery for the maintenance of well-being and life quality of the patients. Thus, I hope that the papers may contribute to loosen the bandages of your routine day and shed some light on your personal surgical interests. Remains to be questioned the difference between reality and truth.

Going in line with the aims and scopes of accurate medical science and the academical conduct of reasoning, our mood tunes in the forms of realities (what) and truth (how). While the latter usually resides hidden, realities model everywhere, making up time, space, and all perceptions that we can think, talk, and speak of, entities ranging from the quantum field dimensions to the huge big space time curve of the universe.

As such realities enter this page and fill this page, as your excited pair of eyes follows these lines, realities enter your life. The beautiful sunny day opens with a lot of surgical routine work and commitments, including patient ward rounds, seeing patients in the outdoor patient service (mirrors), treating patients (shadows) at the ICU; and then there are easier and more complicated cases waiting for you in the OR (comedy). A complex branch anastomosis valve vascular surgery symphony, a minimally invasive concentrated lobe resection of the liver, the glandular pancreas and the scrotum green stomach, some

Prof. Dr. M. Riegler $(\bowtie)$

Reflux Medical, Mariannengasse 10/9, 1090 Vienna, Austria martin.riegler@refluxmedical.com european surgery colonic episodes of diverticulitis have to be terminated by a segment resection of the left-sided colon, including mobilization of the left flexure of the colon, where you have to take care not to damage and harm the spleen. The folding of the cardia resembles the embracement of the arms of the octopus. As a specialized submucosal gland of the esophagus, the thyroid (sister Isis of the esophagus Osiris) sits in the neck and has to be taken out because the nodes became too large and too dangerous, and this needs to be taken into account because it impairs the life quality of the patient (the owner of the thyroid and the nodes). You feel good and you feel better after having demonstrated to yourself that you are doing a great job during a liver, kidney, pancreas, heart, lung transplantation. Brain awaits transplantation. Who may serve as the donor? Who wishes to live the thoughts, spirits, and minds of another person? Surgical incest? Since surgery is not serious, complex, complicated, and difficult enough, man invented politics, power games, and involves him or herself in the power game struggles within the maximal electrical circuit arena of the academics, the surgical departments of the city, county, and rural hospitals (warfare medicine). Even aircraft carriers serve as a mirror for team work and harbor operation theaters and ICUs. As such, energies are spread out and diluted in order to prevent the soldiers from killing their leaders. You are running from date to date, from one appointment to another appointment, from case to case, from fact to reason, from sound to the noise, from network to outflow, from good to evil, from happy to sad, from darkness into the light (Fig. 1). Activities ("stop, foster this and that") serve to justify, sustain, and increase the power of the leaders and their group against the influence of their opponents, competitors, and enemies, who also want to take their position and become a leader of a group. It seems that this conduct of reasoning 


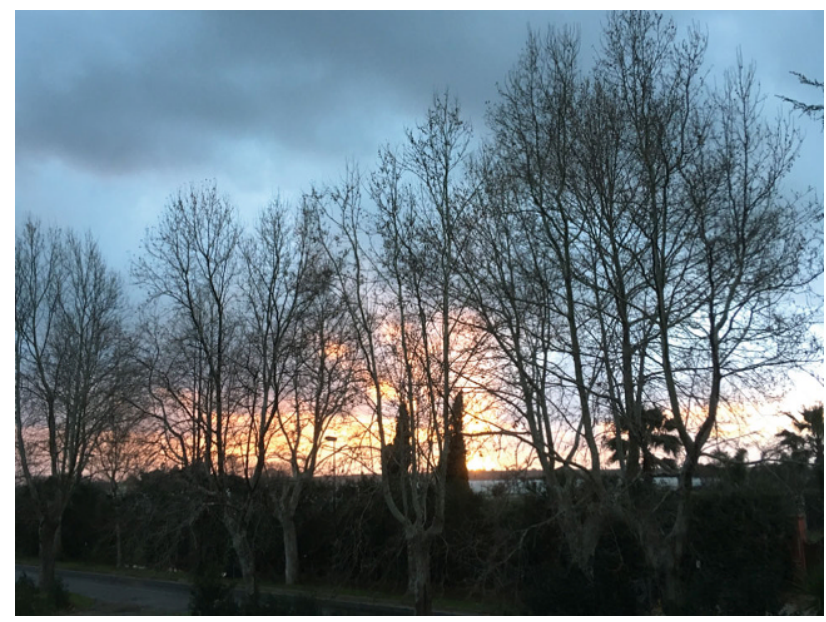

Fig. 1 Image obtained under the winter skies in Paestum, south of Naples, Italy, EU, mirrors the contrasts within the spectrum of our tunes of mood during thinking and reasoning, as outlined in the text

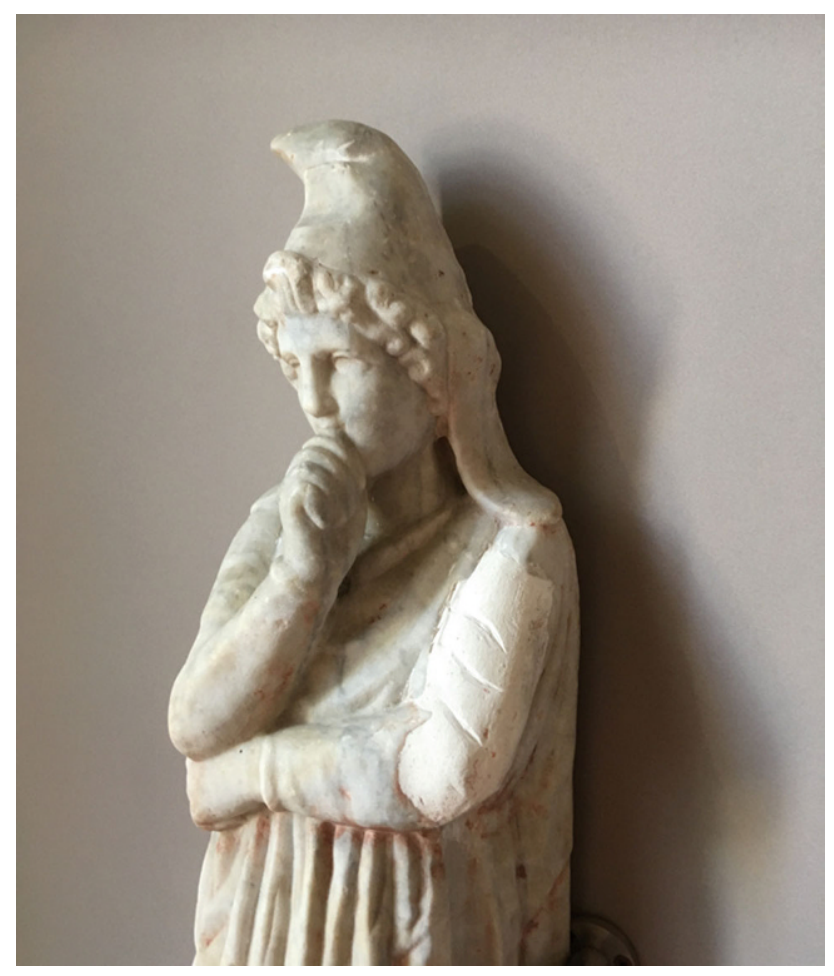

Fig. 2 Image of the statue of a thinker, which had been erected within the Isis temple in Pompeii (first century after Christ). The image mirrors the idea of the author that it is essential to find time for us to step out of the stress of daily life and to find episodes of self-reflection and reasoning

describes a very specific universal behavioral program which is characteristic for plant, animal, and human life, and there seems to be no way to escape these tunes of mood and atmosphere. Going in line with Mark Twain, "Letters from the earth," we have to confess: there seems to exist an archaic area, segment, folding, portion of the brain, which tends to play out power, might, force, envy, hate, greed, thirst,

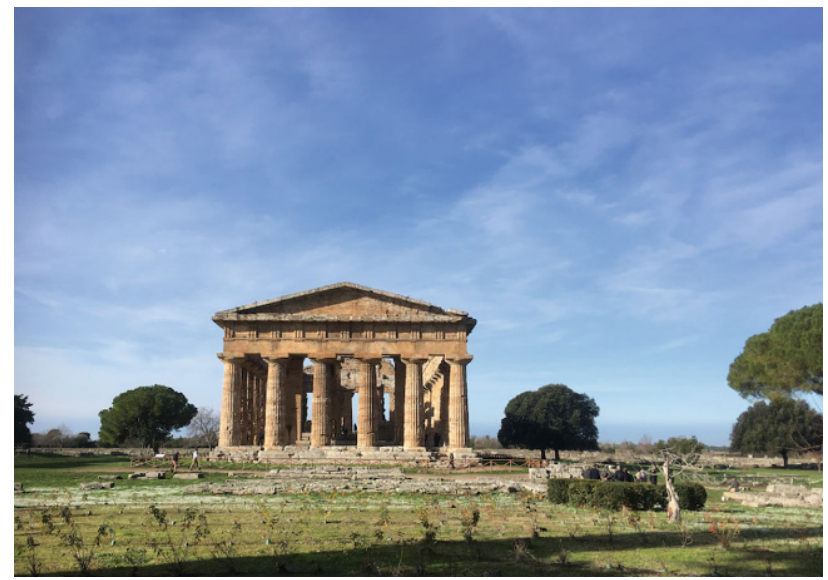

Fig. 3 Poseidon temple at Poseidonia (Paestum), south of Naples, Italy, EU. The temple incorporates the ancient idea that architecture represents a mirror of the skies and heavens, including the semiotics of cosmic knowledge (numbers and the concept of space-time and light!). As such, the temple architecture serves as a time capsule conserving a very ancient legacy of human existence

and hunger (metabolic reason for behavior; Fig. 2). Culture and diet aim to antagonize and outbalance this will for power phenomenon. Of course, culture and diet frequently fail to do so, because humans do not follow culture and diet, art and discipline, and, as such even (academic) surgeons play war, from time to time, time after time within space (the mastery of surgery). Therefore protection does not always work.

Consequently, there is no doubt that all exciting perceptions can be explained as consequences of a single, magic, unique "force": space-time curving. Light sets and traces the signature of space-time. As such, perceptions are visible masses and equal the well-clustered condensations of space-time energy (Fig. 3). Furthermore, the entire energy is in continuous high-speed motion and, therefore, always changes, moves, and swings!! Waves make us fly. change rules the world, the universal swing and, of course, medicine, life, and surgery. What will be your next upcoming case? Who will share your team? Do you like those who you work with? Or do you simply tolerate them? Is it stress, fun, or hope? How is your explanation? Are you allowed to ask those questions on a regular, daily basis? What is now? What is during? How is your moment? Who and what takes you down, up, or keeps you on your track? Is there any weight? What masses up, down, and over? Falling, bending, rejected? So what? Following an accurate and meticulous conduct of reasoning, our recent editorials demonstrated that space-time curving, i. e., gravitation, is highly essential for surgery and profoundly influences surgical procedures. During surgery, major efforts are undertaken to act against the enormous consequences of space-time curving including positioning of the patient, tissues, and organs, and handling of fluids and secretions to foster adequate vision towards the operation field ("where 


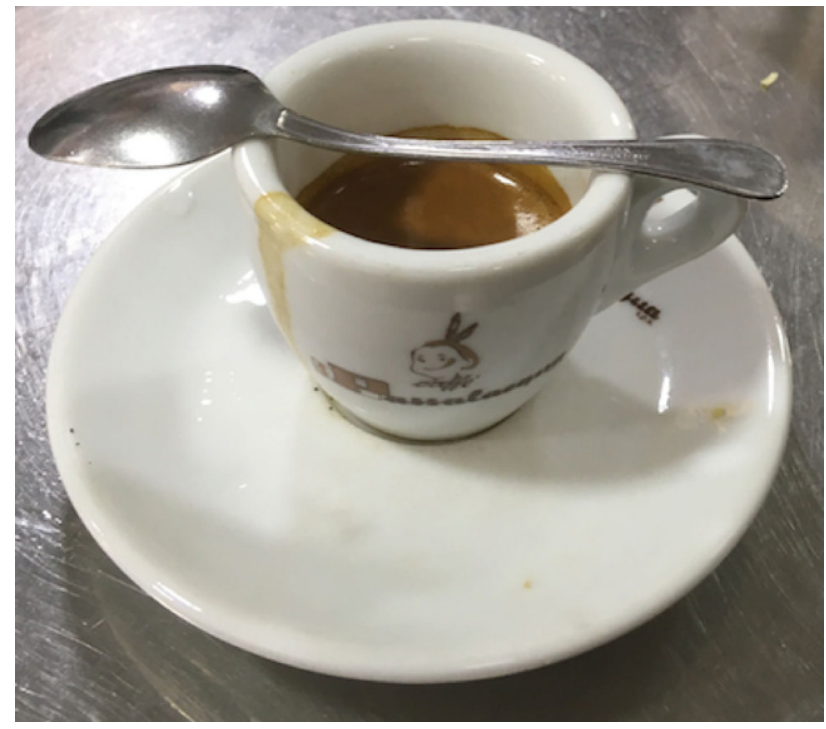

Fig. 4 Cup of Naples-style Italian espresso for a short episode of relaxation during a day full of work and stress, as described and recommended in the text

is my anastomosis?"). Otherwise, lower pelvic, upper abdominal, lateral thoracic, superior brain surgery will get stuck within the process of translation.

You are happy, you are satisfied, the complex case went fine. Find time for a good cup of coffee, you definitely deserve it NOW! (Fig. 4). Congratulations, the sun shines within your heart, light opens your brilliant mind, your mindset would be ready for a new start towards a fascinating new horizon. But you are connected. Here we go. We get interrupted, stopped. The brake! The hero carries his or her blue tooth sword. It seems that you cannot cut yourself out of the digital world. Additional remote realities enter the windows, screens of your cell phone, tablet, and personal computer. Instead of having time to relax, you are forced and kept busy to react and respond to the digital realities, which entered your e-mail, Twitter, Facebook, what is up, university mail account. You manage to learn the simultaneous struggle check of various interconnected parallel activities NOW, decide on multiple matters of fact NOW, clinical, private, educational, financial, ethical, but not mythological, not philosophical. Philosophy only knows one case of emergency, i.e., the truth (see below!). Myths enwrap the truth. As such, the truth appears as a reality. Many of us have lost the ability to speak and understand the signs, languages, and tunes of mythology. What is the case? Here we go! You have to find the solutions to the different realities for your family, sister, brother, friends, your surgical team, science, your boss wants to see you! This information may increase your heart rate, blood pressure. You do not want to talk about your future at the institution NOW! There exist more important issues for you, but, unfortunately, not for your boss. If you are the boss, you may get the stress-evoking information that your financial stock market exchange activities were misled and shocked, and thus the rates for the big villa, the expensive car, the outstanding education of your outstanding children will exceed the income, maybe, now, in the near future. This information gets the leader into a bad mood. As a consequence, this bad mood is transferred to the employee. Seems to be unfair, but this is how it goes. In contrast, the leader could also catch some positive information. This, in turn, mediates a positive and highly motivating atmosphere during the personal communication with the employee. Therefore, we have to understand, possibilities are as important as realities. Maybe possibilities represent realities which have not made it to the surface of perception for the majority. Thus, possibilities and realities should be treated in a similar manner: in the form of manifestations of streams of mood, atmosphere, sound, and being.

The above-mentioned realities and similar stories can happen to every one of us, may happen to every reader of this page. You may learn that your wife, unfortunately, received the diagnosis of lung cancer following a history of cigarette smoking, or breast cancer, after a history of loneliness, or colon cancer after a life-long crusade of constipation. Your husband starts off with prostate cancer or sarcoma, suffers from coronary heart disease, high blood pressure, and rocks into the city of Parry Parkinson Alzheimer. Who knows? You may neglect deeper connections NOW. You feel thoracic pain, a fateful melody of angina pectoris tunes through the chest. You may learn that you are not invincible. Outbalanced, brilliant discipline force is required to run a race, a combat, a market, and institution. Young surgeons, colleagues wish to have a good leader, they wish to be guided by an outstanding authority who meets their requirements. The employees hope that their leader offers platforms for the realization of their ideas, activities, tasks, and undertakings. Authority counts and should incorporate responsibility for the team of coworkers, the best form of authority is the so-called natural authority. Your people do not need a god (statue), hero (Hollywood), not an angle (Skywalker); at best, a leader should simply combine knowledge, gratitude, and humility. However, such an approach may not work for the majority, the majority seems to need the hard hand of a strong leader. Otherwise the system may tend to distort into parts and disarrange into dust. The leader in you counts! Within the tensions of multiple poles, the constituents of a given system reside and fluctuate. But you may not find the time to translate this information into your personal stream of mood, because duty knocks at your door, heart, soul, brain, and it seems that there is no way out. The boss is left alone with his isolated world in his office. Everyone needs attention. Even a leader. Going back to the patient ward, we face young surgeons within their forum. Ave Cesar! They are excited. They are happy to learn that a paper has been accepted 


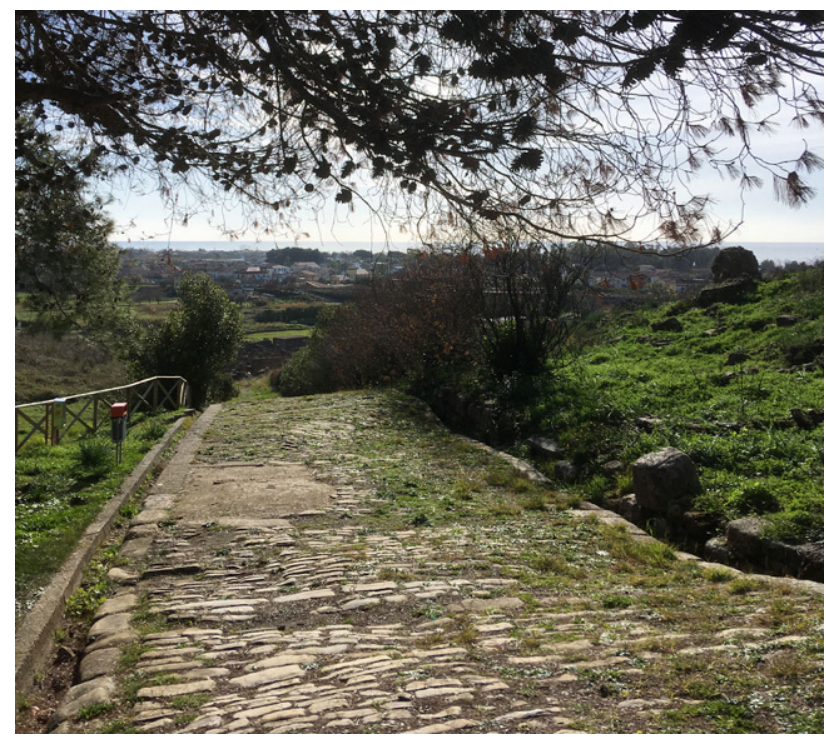

Fig. 5 The remnants of a sidewalk in ancient Elea, south of Paestum, south of Naples, Italy, EU. In Elea, the ancient Greek thinker Parmenides wrote the famous educational poem on truth. He concludes that reasoning and being is the same

for publication in European Surgery. The review had been hard, fair, but the paper included an exceptional set of outstanding data of major importance and relevance. In addition, the paper was well written, structured, and full of innovations, novelties, and actualities. Here we go. Glitter goes gangs, biles go battle, thyroids turn tears, cysts cow the kidney, stress squeezes the adrenals, nodes needle the nurse, pancreas glucose pancakes sugar pantheon, lungs lift the heart rate, lobes little the liver, burning throat cries cucumber, migraine mirrors the apple, eyes eager the ears, endoderm yolk sac yellow the moisture-maker of sound. Disease mirrors embryology. Remains to be questioned the truth (how).

Nothing compares to the truth, and there only exists one truth: the outstanding unique major and essential power-driving force of death. When we die, something goes away and leaves us there in a very different manner. The flash lightning thunder of quietness resolves within the echoes of our minds, thoughts, and inspirations. Here starts the end in the form of art, culture, and myth. This is the atmosphere where medicine started to walk. Therefore, a lot of it still exists and shines within medicine today, within surgery today. When compared to death, when compared to the different shape, atmosphere, color, and mind of death, all realities disappear and become nothing, unimportant, insignificant, and completely vanish, opening our eyes for the only and most important event in our life (after birth). Unfortunately, noone can report on his or her own death. Therefore, we play with models, myths, sounds, imagination, mediation, and sorrow. This is why death equals the truth. Surgery fosters a unique mindset for the bridging of our existence. In contrast to the truth, the rest of the world includes the realities (see above). Statistics draw the line between life and death, without knowing it $(p<0.001)$. Here we speak about the essence of our being, for our reasoning. Most importantly, man struggles with millions of realities in order to avoid confronting him or herself with the truth. Being equals to think death, too (Parmenides was more than clever; Fig. 5). You may ask: why the heaven, why the hell, should a surgeon waste her or his time on thinking about the truth? Because it happens in man, it happens in you, on a daily basis: disease lives the death of health. Let us risk an important utopia: let us step back, hold on for a moment, and step out of the stress struggle waterfront river run business and find a space-time curving sensation for us, individually (Figs. 2, 4 and 5). Risk a quiet moment (Ulysses; Fig. 2). From here you may recharge your battery, reload your brain, and reformat your thoughts, opinions, and reasoning, while earth follows the outbalanced path of the curved space-time around the sun, the moon, the planets, the milky way, the universe, our harmony.

Taken together, it seems reasonable to consider that it may be useful to think about the truth, at least for short, quiet moments every day. This understanding may help you to gain the endurance for the successful management of your realities. As such, your sun may shine, and believe me, everyone, even you dear reader, hides a unique, beautiful sun. So let it shine and be you!

Acknowledgements The author thanks his private and professional environment for stimulation and motivation, which enables the conduct of reasoning reflected in the Editorials. Furthermore, the author thanks all contributors (authors, reviewers, editors, members of the editorial board) of $E u$ ropean Surgery, all young surgeons and scientists and the central European academical societies standing behind $\mathrm{Eu}$ ropean Surgery for their strong support.

Conflict of interest M. Riegler declares that he has no competing interests. 